\title{
High Performance and Meeting Participation: An Observational Study in Software Design Teams
}

\author{
Sabine Sonnentag \\ University of Amsterdam
}

\begin{abstract}
This study compared high and moderate performers' involvement in cooperation processes. The author used an observational method to examine meeting participation of 60 software professionals from 10 software projects. Analyses showed that high performers participated more in the overall meeting process. In poorly structured meetings, high performers contributed more to process regulation activities, such as meeting management, goal setting, problem comprehension, and feedback seeking. No differences in process regulation activities were found for highly structured meetings. Contributions to team processes as a whole differed largely across individual team members, with high performers playing an important role and showing a high adaptation to the specific situational requirements.
\end{abstract}

Modern work organizations need employees who are highly skilled and knowledgeable in their domain. Moreover, because many organizations increasingly rely on teamwork and other cooperative work arrangements, cooperation competencies are required (Cannon-Bowers, Tannenbaum, Salas, \& Volpe, 1995; Stevens \& Campion, 1994).

One area of psychological research that concentrates on the characteristics of highly skilled and knowledgeable individuals is the study of expertise and expert performance (Ericsson \& Lehmann, 1996; Ericsson \& Smith, 1991b). This line of research has a long tradition within cognitive psychology and has been recently adapted to more applied areas of psychology (Ford \& Kraiger, 1995; Sonnentag, 2000). However, until now only a little has been known about how highly skilled and knowledgeable individuals play a part in cooperation

Sabine Sonnentag, Department of Psychology, University of Amsterdam, Amsterdam, the Netherlands.

This research was supported by Grants So 295/1-1 and 1-2 from the German Research Community (DFG), which are gratefully acknowledged. Preliminary results of this study were presented at the International Work Psychology Conference, Sheffield, United Kingdom, July 1998.

I thank Rabea Munzert for her help in categorizing the data.

Correspondence concerning this article should be addressed to Sabine Sonnentag, who is now at the Department of Psychology, University of Konstanz, Postbox 5560 D42, D-78457 Konstanz, Germany. Electronic mail may be sent to sabine.sonnentag@uni-konstanz.de. processes and how they bring to bear their competencies in teamwork settings.

Research on these individuals' involvement in cooperation processes is important in several ways. First, it helps in adapting existing theory on expertise-until now mainly concerned with explaining excellent task accomplishment in individual settings (Ericsson \& Smith, 1991b) - to group work settings that are highly relevant for modern work organizations (West, Borrill, \& Unsworth, 1998). Second, because involvement in cooperation processes offers opportunities for learning, findings on skilled and knowledgeable individuals' participation in cooperation processes can contribute to knowledge about how expertise develops. Third, with respect to team functioning, such study findings add to research to input-process-output models of team functioning (Hackman \& Morris, 1975) and specify how differences between team members are reflected in their contributions to the team process.

This article concentrates on a specific type of cooperative work settings, that is, team meetings. It presents findings from a study that examined differences in meeting participation between highly and moderately performing software professionals.

\section{The Concept of Expertise and High Performance}

Expertise is a relatively broad concept that refers to high, outstanding, and exceptional per- 
formance that is domain-specific, stable over time, and often associated with a well-developed knowledge base (Ericsson \& Smith, 1991a; Ford \& Kraiger, 1995; Green \& Gilhooly, 1992). Furthermore, expertise is assumed to be related to experience and practice (Ford \& Kraiger, 1995; Frensch \& Sternberg, 1989). In this article, I follow the approach proposed by Ericsson and Smith (1991a) and conceptualize expertise as high performance of an individual. On the basis of a number of studies in applied settings (Leithwood \& Steinbach, 1995; Schenk, Vitalari, \& Davis, 1998; Stein, 1995), it is not warranted to equate expertise (i.e., high performance) with years of experience.

Thus, the concept of expertise adopted in this article differs from other expertise concepts, such as representation of group consensus (Turner, 1991) or access to more information (Stewart \& Stasser, 1995). Moreover, although often related at an empirical level (Sonnentag, 1995), at the conceptual level, expertise has to be differentiated from a formal leadership role.

Research on expertise in work settings has revealed a number of differences between high and moderate performers that become obvious in the task accomplishment process. Most of these differences refer to knowledge and problem-solving issues. For example, studies found high performers to possess more complete and more correct domain-specific knowledge, to concentrate more on problem comprehension and goal setting, to show more planning when performing complex and ill-structured tasks, and to put more emphasis on feedback (cf., for reviews, Ericsson \& Lehmann, 1996; Sonnentag, 2000).

\section{High Performers' Involvement in Cooperation Processes}

There are some studies that have addressed the question of whether high and moderate performers differ with respect to their behavior in cooperation situations. In a highly descriptive field study in 17 software development projects, Curtis, Krasner, and Iscoe (1988) found that "exceptional designers" (i.e., highly performing software designers) showed superior communication skills. The authors reported that these persons developed designs for software systems to a great extent while communicating with others. Moreover, they educated other team members during the working process. In a similar manner, Riedl, Weitzenfeld, Freeman, Klein, and Musa (1991) also reported high interpersonal skills in expert software engineers.

In an interview study, Sonnentag (1995) found that coworkers described excellent software professionals as highly socially competent. Furthermore, excellent software professionals themselves reported that they spent more time on specific work activities that asked for a high amount of communication, such as consultations within the team and participation in review meetings. Stein (1995) studied high and moderate performers in a bio-technology start-up firm and an educational institution. He found that high performers were highly trusted by their network members and were perceived to have high leadership qualities.

Leithwood and Steinbach (1995) used a stimulated recall method to study elementary school principals' behavior during staff meetings. The authors found substantial differences between the activities of highly performing and more typical school principals. High performers stimulated more participation of the other teammembers and paid more attention to the larger context of the problems to be discussed as well as their long-term consequences. Thus, high performers' meeting behavior showed great similarities to their behavior in individual task settings, such as emphasis on problem comprehension and planning.

Taken together, these studies suggest that high performers differ from moderate performers not only with respect to problem-solving processes and knowledge when performing tasks in individual settings, but also with respect to their involvement in cooperation processes.

Despite this relatively consistent picture, most studies share two major shortcomings that make it difficult to arrive at a conclusive interpretation of the research findings. First, studies rely mainly on self-reports and same-source data in which both the identification and description of high performers were provided by peers. Studies based on observational data are rare. Therefore, one cannot rule out the possibility that high performers just reported more cooperation and communication activities without really showing these activities to a greater extent. The same might be true for descriptions provided by peers. Because of a general halo effect, peers might overestimate the communi- 
cation and cooperation skills of those they perceive to be high performers.

Second, research has shown that high and moderate performers' work situations differ in some aspects (Sonnentag, 1995; Stein, 1995). Therefore, some studies compared only high and moderate performers who worked at the same hierarchical level (e.g., Sonnentag, 1995). However, one must remember that the more specific task requirements that have to be met by high and moderate performers might be unequal. It might be that the task requirements present in high performers' work situations ask for more communication and cooperation activities. For arriving at an unequivocal conclusion about high and moderate performers' cooperation activities, it is therefore necessary to study a cooperation setting in which high and moderate performers face the same requirements.

To overcome shortcomings of previous research, I studied team meetings as a type of cooperation setting. First, in team meetings, it is relatively easy to observe cooperation processes. Second, with the exception of the team leader, all meeting participants are faced with similar requirements during the meeting process.

\section{High Performers' Participation in Team Meetings}

Team meetings are a specific type of cooperation setting aimed at exchanging information, problem solving, decision making, or facilitating solution acceptance and execution (Cox, 1987; Kriesberg \& Guetzkow, 1950; Schwartzman, 1989). Moreover, in some professional areas, crucial parts of the work are accomplished in meetings. For example, in software design, new design solutions are developed and evaluated during team meetings (Freedman \& Weinberg, 1982; Olson, Olson, Carter, \& Storrøsten, 1992; Walz, Elam, Krasner, \& Curtis, 1987). A study in software development teams showed that software professionals spent about $11 \%$ of their weekly working time in review and other formal meetings and an additional $7 \%$ in informal meetings (Sonnentag, 1995).

Until now, most research about the relationship between cooperation processes and performance addressed this relationship at the group level and identified a number of activities that are important for high group performance (Guzzo \& Shea, 1992; Tannenbaum, Salas, \&
Cannon-Bowers, 1996; West et al., 1998). However, if one is interested in the relationship between high individual performance and cooperation processes, one has to shift the research focus to the individual level. Then, one of the main question becomes whether individual teammembers differ in the extent to which and the way in which they contribute to the cooperation processes within the group.

High performers possess more domain-specific knowledge and know more about successful working strategies (Smith \& Good, 1984; Sonnentag, 1998; Wagner \& Sternberg, 1985). One can assume that this knowledge and these task accomplishment procedures not only are relevant for task accomplishment in individual settings, but also are important and helpful in cooperative work settings. This assumption implies that because of their superior domainspecific knowledge, high performers can contribute more to the group's task accomplishment process. Their knowledge enables them to give answers to emerging questions and to provide others with necessary information.

In addition, high performers show a better mastery of the task and the underlying cognitive processes. Framed in terms of resource allocation theory (Kanfer \& Ackerman, 1989), high performers therefore need less resources for ontask activities. For example, they will need less cognitive resources for basic problem-solving issues. As a consequence, they have more resources available for other activities, such as a communication and cooperation activities. Thus, one can assume that high performers contribute more to the overall meeting process than do moderate performers. To sum up, one can assume that high performers are more involved in the cooperation process than are moderate performers. Research on problem-solving groups has shown that group members with a high degree of actual expertise show a higher degree of participation within a group discussion (Bottger, 1984).

Hypothesis 1: High performers will show a higher overall participation in team meetings than moderate performers.

In addition, one might assume that high performers not only contribute more to the overall meeting process, but also show a higher participation in those activities that are highly relevant for good team-level performance. Earlier research has described activities that regulate 
the group process and that are highly important for high group performance. These process regulation activities include goal setting, problem analysis, and feedback seeking (Jehn \& Shah, 1997; Stasser \& Stewart, 1992; Tschan, 1995; Weldon, Jehn, \& Pradhan, 1991; Weldon \& Weingart, 1993). Moreover, in the context of meetings, meeting management (i.e., the coordination of individual contributions and reflection about the cooperation process) is necessary for successful task accomplishment (Fischer \& Northey, 1993; Larson, Christensen, Abbott, \& Franz, 1996; Maier, 1967; cf. also West, 1996).

Research on expertise has shown that when high performers work on a task in an individual setting, they approach this task in a specific way and show more process regulation activities. This finding implies that compared with moderate performers, high performers set more goals and focus more on their work priorities (Hacker \& Vaic, 1973; Tripoli, 1998; Vitalari \& Dickson, 1983), put more emphasis on problem comprehension (Klemp \& McClelland, 1986; Leithwood \& Steinbach, 1995; Sonnentag, 1998), seek more feedback (Ashford \& Tsui, 1991; Sonnentag, 1998), and reflect more about their process of task accomplishment (Dörner \& Schölkopf, 1991). One can assume that high performers' specific approach to accomplishing tasks is not restricted to individual settings; rather, one can expect that they show a similar behavior in cooperation settings. A study on construction processes revealed that a person who analyzes and plans a lot in an individual setting shows a similar approach to task accomplishment when working in a group (BadkeSchaub \& Frankenberger, 1996). Therefore, one might come to the conclusion that high performers show generally more process regulation activities, that is, more goal setting, problem analysis, feedback seeking, and meeting management.

However, Ericsson and Lehmann (1996) described adaptation to task requirements and task constraints as one of the core characteristics of high performers, which implies that high performers succeed in fitting their behavior to the necessities of the task. For example, results from empirical studies on high performers' planning activities support this notion: High performers show a high amount of planning only in ill-structured situations (i.e., when the situation requires planning) but not in well- structured situations in which no planning is necessary (Leithwood \& Steinbach, 1995; Tripoli, 1998). One can assume that the same pattern applies to process regulation within team meetings: High performers will participate substantially more in process regulation when the meeting requires this activity, that is, when no clear structure has been imposed on the meeting beforehand. In such poorly structured meetings, in which it is not decided in advance how to discuss specific topics and how to schedule individual contributions, process regulation during the meeting is highly required. Compared with moderate performers, high performers will show more of these process regulation activities needed in such a situation. However, in wellstructured meetings, in which decisions about how to proceed are already made in advance and in which less process regulation is necessary, the difference between high and moderate performers' participation in process regulation decreases.

Hypothesis 2: In unstructured meetings, high performers will show a higher participation in process regulation activities than moderate performers. In highly structured meetings, high and moderate performers' participation in process regulation activities will not differ.

\section{Method}

\section{Sample}

The study was conducted in 10 software development teams located in various parts of Germany. Within each team, one meeting was observed and analyzed. In total, 60 persons participated in the meetings. The number of participants per meeting ranged between 3 and 8 $(M=6.0, S D=2.2)$. Participants' mean age was 33.2 years $(S D=4.9)$. Mean professional experience in software development varied between a few weeks and 25 years $(M=7.1$ years, $S D=5.1$ ). Eleven of the 60 meeting participants were women $(18 \%)$. The percentage of women did not differ across teams, $\chi^{2}(9, N=$ $60)=12.25, n s$.

The teams were first contacted by mail. Then, more information about the study was given by phone. The teams were invited to participate in a scientific study on effectiveness in software development, which in this case would imply an observation of a regular project meeting. As 
inducement for participating, teams were offered a feedback session about the quality of their team meetings and about how they could improve them. These feedback sessions, specifically designed for each participating team, were scheduled up to 8 weeks after data collection.

The observed meetings were project meetings that were held in the participating teams on a more or less regular basis. The project teams themselves decided about their meetings' content and agendas. The duration of a meeting ranged between 62 and $165 \mathrm{~min}(M=100.3$; $S D=38.4$ ). In all meetings, the team leader served as the meeting facilitator. In one meeting (Meeting 7), a deputy team leader was present in addition to the team leader.

Characteristics of the studied project teams and team meetings are summarized in Table 1. There was some variation with respect to the frequency of meetings. Most teams met four times a month (i.e. once a week). The participating software teams developed a wide range of software systems. Applications included information and communication systems for administrative and logistic purposes as well as an expert system. One project concentrated on the adaptation of English language software systems to the German market. Moreover, at the time of data collection, the studied teams were in different phases of the software life cycle, ranging from an early design phase to maintenance of software systems already in use. Using video observations of the meeting processes, I analyzed the meeting content (see Table 1). On average, $53 \%$ of meeting time was spent on project organization $(S D=33.8), 30 \%$ on product development $(S D=32.1)$, and $17 \%$ on product evaluation $(S D=18.6)$. Overall, there was a large variation across the meetings with respect to software to be developed, software life cycle, and meeting content.

\section{Procedure}

Data for this study were gathered in two phases. In the first phase, peer nominations were held in the participating teams. In the second phase, which took place 2 to 6 weeks after the first phase, project meetings were observed onsite and were videotaped. During the videotaping, the observer was present in the meeting room. In an informal evaluation after the meet-

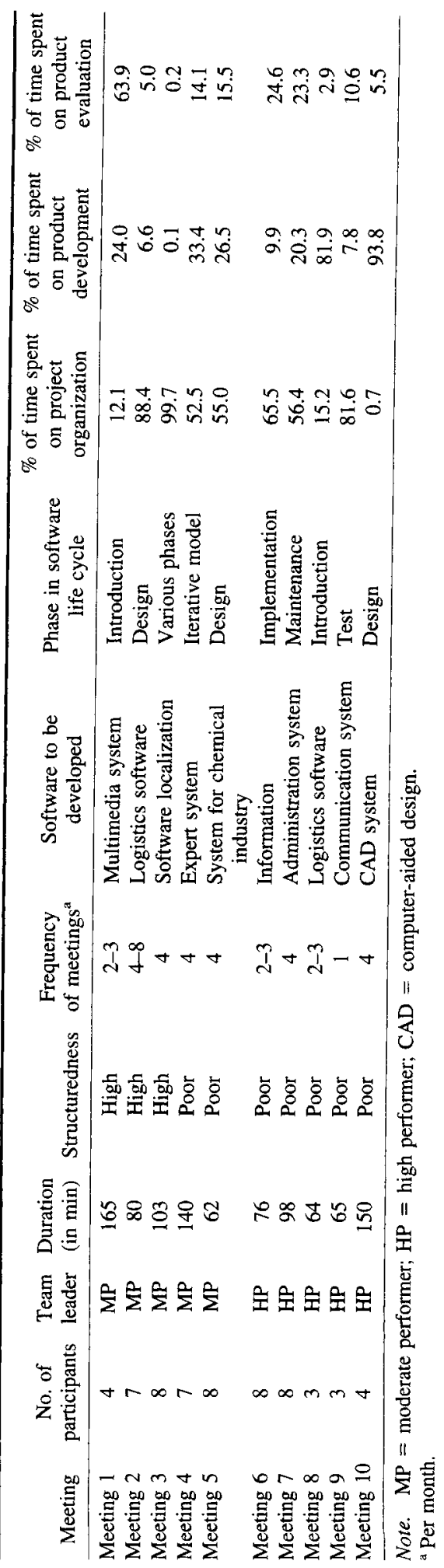


Table 2

Number of High and Moderate Performers Across Teams

\begin{tabular}{ccccccc}
\hline & $\begin{array}{c}\text { Total no. } \\
\text { of } \\
\text { participants }\end{array}$ & $\begin{array}{c}\text { HP in } \\
\text { leadership } \\
\text { role }\end{array}$ & $\begin{array}{c}\text { HP without } \\
\text { leadership } \\
\text { role }\end{array}$ & $\begin{array}{c}\text { MP in } \\
\text { leadership } \\
\text { role }\end{array}$ & $\begin{array}{c}\text { MP without } \\
\text { leadership } \\
\text { role }\end{array}$ & $\begin{array}{c}\text { Participants } \\
\text { nominated } \\
\text { beting coworker }\end{array}$ \\
\hline Meeting 1 & 4 & 0 & 1 & 1 & 1 & 1 \\
Meeting 2 & 7 & 0 & 2 & 1 & 4 & 0 \\
Meeting 3 & 8 & 0 & 1 & 1 & 5 & 1 \\
Meeting 4 & 7 & 0 & 2 & 1 & 4 & 0 \\
Meeting 5 & 8 & 0 & 1 & 1 & 5 & 0 \\
Meeting 6 & 8 & 1 & 1 & 0 & 6 & 0 \\
Meeting 7 & 8 & 1 & 3 & 0 & 4 & 0 \\
Meeting 8 & 3 & 1 & 0 & 0 & 2 & 0 \\
Meeting 9 & 3 & 1 & 0 & 0 & 3 & 0 \\
Meeting 10 & 4 & 1 & 0 & 0 & 36 & 3 \\
Total & 60 & 5 & 11 & 5 & & 0 \\
\hline
\end{tabular}

Note. $\mathrm{HP}=$ high performer; $\mathrm{MP}=$ moderate performer.

ings, meeting participants reported that the meetings had been typical for the meetings normally held.

\section{Measures}

Performance level. Prior to the meetings, performance level was assessed in a peer nomination procedure. In a questionnaire, all teammembers were asked to name a coworker they regarded as a highly performing software professional. Participants filled in the questionnaires individually and returned the questionnaires in a stamped, addressed envelope directly to the university. Participants were assured that their nominations were kept confidential.

For further analyses, those who were nominated by at least two of their coworkers were considered to be high performers. Those not named at all were considered to be moderate performers. Those named by one of their coworkers were excluded from the statistical comparisons between high and moderate performers. ' Study participants did not receive any information about who was nominated as a high performer. On average, $80 \%(S D=7.7)$ of the teammembers agreed on who was a high performer and who was not.

The question of whether outcomes from peer nominations correspond to actual task performance was addressed in another study (Sonnentag, 1998). Analysis in that study showed that highly performing software professionals identified by a peer nomination procedure identical to that used in the present study outperformed moderate performers when accomplishing a software design task-with software design task performance assessed by an objective performance measure (algorithm quality, modularity, comprehensibility, and detail of the design solution).

Table 2 shows the composition of all teams. In total, 16 participants were identified as high performers by at least 2 of their coworkers. In 5 of the 10 meetings, team leaders were nominated as highly performing software professionals. In the other 5 meetings, team leaders were not nominated as high performers. In 2 meetings in which team leaders had been nominated as high performers, there were also other teammembers who were nominated as high performers (Meetings 6 and 7). Overall, there was a tendency to name team leaders more frequently as high performers, $\chi^{2}(1, N=60)=2.89, p=$

\footnotetext{
${ }^{1}$ In total, 3 persons were named by only one of their coworkers as high performers. Although they were excluded from the statistical comparisons between high and moderate performers, these persons are included in the descriptive statistics presented in Tables 4 and 5 . In these tables, they were subsumed under the category of moderate performers. Although it was not explicitly encouraged, participants were free to name themselves as a high performer. One participant in Meeting 5 nominated himself. This person was not nominated by anyone else. By adopting a conservative hypothesis testing strategy, I disregarded this self-nomination in further analysis; thus, this person was treated as if not nominated by anybody. In an additional analysis, this person was excluded from the comparisons between high and moderate performers - as was any other person named only once. Exclusion of this person from the analyses did not alter the results.
} 
.0892. High and moderate performers did not differ with respect to years of professional experience $(M=8.6, S D=6.8$ for high performers; $M=6.1, S D=3.4$ for moderate performers), $t(18.55)=1.37 ; n s ; d=0.48$.

Overall meeting participation. Team meetings were videotaped, and these tapes were later analyzed segment by segment. One segment consisted of one uttered statement, usually a phrase. I performed the segmentation. Overall meeting participation was the total number of statements a participant contributed to the meeting.

Participation in process regulation activities. Statements concerning meeting management and statements contributing to goal setting, problem comprehension, and feedback seeking were coded as process regulation activities. Table 3 provides descriptions and examples for these categories. All other statements not referring to meeting management, goal setting, problem comprehension, and feedback seeking were categorized as non-process-regulation statements. I performed these ratings. To determine interrater reliability, a second rater coded a total of 989 segments from five randomly selected meetings. Interrater agreement was $76 \%$, corresponding to a Cohen's kappa of .66, which can be regarded as a good reliability (Landis \& Koch, 1977). Both raters were blind to the peer nomination outcomes.

Structuredness of the meeting. I assessed whether the sequence of individual contributions to the meeting process had been scheduled in advance. In highly structured meetings, there was a planned sequence for each person to speak, so individual contributions followed a relatively fixed scheme. In relatively unstruc-

Table 3

Category System for Analyzing Process Regulating Activities

\begin{tabular}{|c|c|c|}
\hline Category & Description & Example \\
\hline Meeting management & $\begin{array}{l}\text { Contributions that structure the } \\
\text { meeting: } \\
\text { - setting the agenda } \\
\text { - moving from one topic to } \\
\text { another } \\
\text { - suggestions about further } \\
\text { topics to be discussed } \\
\text { - overall and in-between } \\
\text { summaries }\end{array}$ & $\begin{array}{l}\text { "Today, we should talk about the } \\
\text { status of our project." }\end{array}$ \\
\hline Goal setting & $\begin{array}{l}\text { Contributions concerning } \\
\text { - project goals and about what } \\
\text { has to be done } \\
\text { - requirements the product to } \\
\text { be developed should meet } \\
\text { - requirements the already } \\
\text { developed product should } \\
\text { meet }\end{array}$ & $\begin{array}{l}\text { "We should always have a } \\
\text { meeting in the last week of } \\
\text { each month." } \\
\text { "Our error-handling procedures } \\
\text { should meet the following } \\
\text { criteria: ..." } \\
\text { "It is not enough if the finished } \\
\text { module is consistent in itself, } \\
\text { it also must be easily } \\
\text { maintainable." }\end{array}$ \\
\hline $\begin{array}{l}\text { Problem } \\
\text { comprehension }\end{array}$ & $\begin{array}{l}\text { Requesting information about } \\
\text { - project organization } \\
\text { - product or solution to be } \\
\text { developed } \\
\text { - already existing product } \\
\text { developed by the team }\end{array}$ & $\begin{array}{l}\text { "Will we continue with our } \\
\text { hotline service? When will it } \\
\text { be installed?" } \\
\text { "Is it possible to develop a } \\
\text { global list of return-codes?" } \\
\text { "Can you explain in detail how } \\
\text { this works?" }\end{array}$ \\
\hline Feedback seeking & $\begin{array}{l}\text { Questioning and asking } \\
\text { feedback about } \\
\text { - reports and plans concerning } \\
\text { project organization } \\
\text { - solution ideas and concepts } \\
\text { - already existing product } \\
\text { developed by the team }\end{array}$ & $\begin{array}{l}\text { "Is it really feasible that you can } \\
\text { finish this part by Monday?" } \\
\text { "Is this correct? Let's go through } \\
\text { it in detail ..." } \\
\text { "I have to ask this once again: } \\
\text { All these icons that we } \\
\text { introduced here, they are used } \\
\text { consistently, aren't they?" }\end{array}$ \\
\hline
\end{tabular}


tured meetings, the sequence of speakers evolved during the meeting process. Nevertheless, the relatively unstructured meetings had previously set agendas that were supposed to guide the meeting process.

\section{Analysis}

The study followed a quantitative case study approach (Yin, 1981). In a first step, all 10 meetings were analyzed separately. Within the 10 meetings, segments constituted the units of analysis (McClintock, Brannon, \& Maynard, 1979). In a second step, additional Wilcoxon tests across the meetings were performed.

Previous research has shown that high performers more often work in formal leadership positions (Sonnentag, 1995; Stein, 1995) and that team leaders contribute very much to the meeting process (Larson et al., 1996). Also, in the present study, team leaders tended to be more often nominated as high performers. This finding implies that a person's formal role within the meeting was confounded with this person's performance level. Thus, if a high performer who was at the same time the team leader contributed significantly more to the meeting than other members, one cannot decide whether this extensive contribution was due to this person's formal leadership role or to his or her high performance level. Therefore, I performed two sets of analyses. The first set included only meeting participants without a formal leadership role: I compared high performers with moderate performers. In the second set, I compared high performers with formal leadership roles with moderate performers who did not have a formal leadership role.

\section{Results}

\section{Participation of High Performers With No Formal Leadership Role}

In the first set of analyses, I compared meeting participation of high performers who were not team leaders with meeting participation of moderate performers who also were not team leaders. These analyses were based on seven meetings, that is, the five meetings in which the identified high performers were not the team leaders and the two meetings in which other teammembers than team leaders had been nom- inated as high performers. For these analyses, all team leaders and the deputy team leader present in Meeting 7 were excluded from analyses.

The upper two sections of Table 4 display the comparison of overall meeting participation between high and moderate performers. In four meetings (Meetings 1, 3, 4, and 5), high performers showed a significantly higher degree of overall participation than did moderate performers. In Meeting 2, the same pattern emerged, with the difference between high and moderate performers being marginally significant. Thus, in all meetings in which the team leaders were not regarded as being high performers, high performers were more involved in the overall meeting process. ${ }^{2}$

However, in Meetings 6 and 7 a different picture emerged. Compared with moderate performers, high performers did not participate more in these meetings. In Meeting 6, high performers' degree of participation was even significantly lower than that of the moderate performers. Meetings 6 and 7 were the two meetings in which the team leaders were also nominated as high performers and participated to a high extent in the meeting process. It seems that in these two meetings a "role differentiation" (Turner \& Colomy, 1988) took place between high performers who were the team leaders and high performers who were not the team leaders. In teams in which more than one person was a high performer and one person was highly involved in the meeting process because of his or her formal leadership role, the other high performer might have defined a role for him- or herself that was highly different from the role of the team leader who was also a high performer.

\footnotetext{
${ }^{2}$ One might argue that it is not warranted to apply chisquare tests because the observations within the meetings were not completely independent. To address this objection, I conducted additional tests with the overall meeting participation data. To reduce the interdependence among measures observed over time, Altman (1979) suggested analyzing only a portion of the available data. In the present study, analysis was based on every 10th segment of the overall meeting participation data. $Q$ difference tests with meeting participants as repeated measurement factors were performed. Results remained the same, with two exceptions: In Meeting 2, the difference between high and moderate performers did not reach the significance level. In Meeting 6, in which a result contrary to the hypothesis had been found, the difference was not significant any longer.
} 
Table 4

Meeting Participation of Members Without Formal Leadership Role:

Comparison Between High and Moderate Performers

\begin{tabular}{|c|c|c|c|c|c|c|c|}
\hline \multirow[b]{2}{*}{ Meeting } & \multicolumn{2}{|r|}{$\mathrm{HP}$} & \multicolumn{2}{|r|}{ MP } & \multicolumn{3}{|c|}{ Comparison of HP \& MP } \\
\hline & $\begin{array}{l}\text { Mean } \% \text { of } \\
\text { statements }\end{array}$ & $\begin{array}{l}\text { No. of participants } \\
\text { in this category }\end{array}$ & $\begin{array}{l}\text { Mean } \% \text { of } \\
\text { statements }\end{array}$ & $\begin{array}{l}\text { No. of participants } \\
\text { in this category }\end{array}$ & $x^{2}$ & $d f, N^{\mathrm{a}}$ & $\begin{array}{l}\text { No. of } \\
\text { segments }\end{array}$ \\
\hline \multicolumn{8}{|c|}{ Overall meeting participation: Structured meeting situation } \\
\hline Meeting 1 & 25.2 & 1 & 8.1 & 2 & $111.67^{* *}$ & 2,503 & 503 \\
\hline Meeting 2 & 12.1 & 2 & 10.4 & 4 & $3.29^{\mathrm{b}}$ & 5,566 & 566 \\
\hline Meeting 3 & 10.7 & 1 & 5.0 & 6 & $45.63 * *$ & 6,361 & 361 \\
\hline \multicolumn{8}{|c|}{ Overall meeting participation: Unstructured meeting situation } \\
\hline Meeting 4 & 13.7 & 2 & 9.6 & 4 & $31.60^{* *}$ & $5,1,037$ & 1,037 \\
\hline Meeting 5 & 10.6 & 1 & 6.2 & 6 & $16.26^{* *}$ & 6,248 & 248 \\
\hline Meeting 6 & 4.7 & 1 & 6.5 & 6 & $4.08 *$ & 6,384 & 384 \\
\hline Meeting 7 & 8.3 & 3 & 8.9 & 3 & 0.41 & 5,409 & 409 \\
\hline \multicolumn{8}{|c|}{ Participation in process regulation: Structured meeting situation } \\
\hline Meeting 1 & 2.0 & 1 & 2.7 & 2 & 1.64 & 2,22 & 22 \\
\hline Meeting 2 & 5.0 & 2 & 8.8 & 4 & $4.23^{*}$ & 5,80 & 80 \\
\hline Meeting 3 & 6.3 & 1 & 4.8 & 6 & 0.48 & 6,60 & 60 \\
\hline \multicolumn{8}{|c|}{ Participation in process regulation: Unstructured meeting situation } \\
\hline Meeting 4 & 12.7 & 2 & 8.8 & 4 & $7.51^{* *}$ & 5,224 & 224 \\
\hline Meeting 5 & 7.1 & 1 & 3.6 & 6 & $-^{c}$ & 6,28 & 28 \\
\hline Meeting 6 & 10.2 & 1 & 4.9 & 6 & $8.21 * *$ & 6,78 & 78 \\
\hline Meeting 7 & 5.3 & 3 & 5.8 & 3 & 0.16 & 5,57 & 57 \\
\hline
\end{tabular}

Note. $\mathrm{HP}=$ high performer; $\mathrm{MP}=$ moderate performer.

${ }^{\mathrm{a}} N=$ no. of segments. ${ }^{\mathrm{b}} p=.077$. ${ }^{\mathrm{c}}$ Because of the small number of statements, a chi-square was not applicable $\left(\mathrm{f}_{\mathrm{e}}=0.17 ; \mathrm{f}_{\mathrm{o}}=0.36 ; p<.01\right)$.

${ }^{*} p<.05 . \quad{ }^{* *} p<.01$.

Across all seven meetings, high performers' overall meeting participation was $12 \%(S D=$ 6.4), and moderate performers' participation was $8 \%(S D=2.0)$, Wilcoxon test; $p<.05$; $d=1.05$. Taken together, Hypothesis 1 was confirmed.

The lower two sections of Table 4 reports the results on participation in process regulation activities. Because of a great variation between the meetings and small numbers of some specific process regulation activities, the several process regulation measures were collapsed into one process regulation measure (Cronbach's $\alpha=.90)$. In structured meetings, high performers did not participate more in process regulation than did moderate performers. In Meeting 2 , high performers on average even showed less process regulation activities than did moderate performers.

In three of the four unstructured meetings, high performers showed more process regu- lation activities than did moderate performers. They were more involved in managing the meeting, formulated more goals, and contributed more to problem analysis and feedback processing. Thus, especially in those situations that were not highly structured in advance and therefore required structuring by the meeting participants, high performers provided the necessary structure by process regulation activities. However, Meeting 7 did not show the same pattern. High performers did not participate more in process regulation activities than did moderate performers. A reason for this finding might be the specific composition of the team. Two of the three high performers were employed by an external consulting firm and not by the company in which the meeting took place. Therefore, they might have been less involved in the meeting process, particularly in process regulation activities. 
Table 5

Meeting Participation: Comparison Between High Performers in Leadership Roles and Moderate Performers

\begin{tabular}{|c|c|c|c|c|c|c|c|}
\hline \multirow[b]{2}{*}{ Meeting } & \multicolumn{2}{|c|}{ HP in leadership role } & \multicolumn{2}{|c|}{ MP (no leadership role) } & \multicolumn{3}{|c|}{ Comparison of HP \& MP } \\
\hline & $\begin{array}{c}\text { Mean \% of } \\
\text { statements }\end{array}$ & $\begin{array}{l}\text { No. of participants } \\
\text { in this category }\end{array}$ & $\begin{array}{l}\text { Mean \% of } \\
\text { statements }\end{array}$ & $\begin{array}{l}\text { No. of participants } \\
\text { in this category }\end{array}$ & $x^{2}$ & $d f, N^{\mathrm{a}}$ & $\begin{array}{l}\text { No. of } \\
\text { segments }\end{array}$ \\
\hline \multicolumn{8}{|c|}{ Overall meeting participation: Unstructured meeting situation } \\
\hline Meeting 6 & 56.1 & 1 & 6.5 & 6 & $1,354,04 * *$ & 6,834 & 834 \\
\hline Meeting 7 & 33.5 & 1 & 8.9 & 3 & $238.86^{* *}$ & 3,476 & 476 \\
\hline Meeting 8 & 57.6 & 1 & 21.2 & 2 & $220.16^{* *}$ & 2,834 & 834 \\
\hline Meeting 9 & 83.4 & 1 & 8.3 & 2 & $591.00^{* *}$ & 2,524 & 524 \\
\hline Meeting 10 & 36.4 & 1 & 21.2 & 3 & $122.71 * *$ & $3,1,756$ & 1,756 \\
\hline \multicolumn{8}{|c|}{ Participation in process regulation: Unstructured meeting situation } \\
\hline Meeting 6 & 60.2 & 1 & 4.9 & 6 & $400.10^{* *}$ & 6,176 & 176 \\
\hline Meeting 7 & 39.5 & 1 & 5.8 & 3 & $102.98^{* *}$ & 3,98 & 98 \\
\hline Meeting 8 & 47.2 & 1 & 26.4 & 2 & $11.06^{* *}$ & 2,127 & 127 \\
\hline Meeting 9 & 97.3 & 1 & 1.4 & 2 & $286.49^{* *}$ & 2,146 & 146 \\
\hline Meeting 10 & 36.1 & 1 & 21.3 & 3 & $15.08 * *$ & 3,230 & 230 \\
\hline
\end{tabular}

Note. $\mathrm{HP}=$ high performer; $\mathrm{MP}=$ moderate performer.

** $p<.01$.

${ }^{\text {a }} N=$ no. of segments.

Across the four unstructured meetings, high performers' participation in process regulation was 9\% ( $S D=3.3)$. Moderate performers' contribution was $6 \%(S D=2.2)$, Wilcoxon test; $p=.0625 ; d=1.09$. Across the three structured meetings, high performers' $(M=4.4 \%, S D=$ 2.2) and moderate performers' $(M=5.4 \%, S D$ $=3.1$ ) participation in process regulation did not differ, Wilcoxon test; $n s ; d=-0.38$. Thus, Hypothesis 2, was confirmed.

\section{Participation of High Performers With Formal Leadership Roles}

In the second set of analyses, I compared the participation of high performers who were also team leaders with the participation of moderate performers. Other high performers who were not team leaders (Meetings 6 and 7) and the deputy team leader participating in Meeting 7 were excluded from these analyses. Because all five of these meetings where unstructured, only the first part of Hypothesis 2 could be tested.

Table 5 shows the results of the five meetings in which the persons nominated as high performers were also team leaders. Compared with moderate performers, high performers in formal leadership roles participated more in the meeting with respect to both overall meeting partic- ipation (Wilcoxon test; $p<.05 ; d=2.07$ ) and participation in process regulation (Wilcoxon test; $p<.05 ; d=1.70) .{ }^{3}$ Thus, for high performers with formal leadership roles, both $\mathrm{Hy}$ pothesis 1 and the first part of Hypothesis 2 were supported. It seems that the persons who were high performers and team leaders played a very prominent role in all these meetings. On average, these persons' overall meeting participation was $53 \%(S D=20.1)$, and their average participation in process regulation activities was $56 \%(S D=24.9)$. Analysis of covariance with team size as covariate showed that these high performers who were also team leaders contributed more to the overall meeting, $F(1,13)=$ $26.24, p<.01, d=2.79$, and to process regulation, $F(1,13)=26.81, p<.01, d=2.74$, than did high performers who were not team leaders.

Team leaders who were not high performers contributed $48 \%(S D=12.6)$ to the overall

\footnotetext{
${ }^{3}$ There was one freelance consultant present in Meeting 9. This person was a moderate performer. Similar to the interpretation given with respect to Meeting 7 , one could argue that in Meeting 9 moderate performers contributed less to the overall meeting and process regulation activities because one of the moderate performers was this freelance consultant. When excluding this freelance consultant from the analyses, however, the results did not change.
} 
meeting process and $65 \%(S D=19.8)$ to process regulation. There were no significant differences in meeting participation between team leaders who were high performers and team leaders who were not, both for overall participation, $F(1,7)=0.00, n s, d=0.35$, and for participation in process regulation, $F(1,7)=$ $1.05, n s ; d=-0.38$.

\section{Discussion}

This study examined high and moderate performers' participation in team meetings. In the great majority of the analyzed meetings, high performers showed a greater overall participation in the meeting process. High performers participated more in process regulation activities when the meeting was unstructured but not when the meeting was highly structured.

On the basis of observational data, this study confirms and extends findings from earlier research (e.g., Leithwood \& Steinbach, 1995; Sonnentag, 1995). High performers are highly involved in cooperation processes and play a prominent role in team-work settings. In addition, they do not show the same kind of participation across all situations. They contribute more to process regulation only in situations that ask for structure but not in situations that are highly structured in advance. This finding supports the notion that high performers show high adaptation to task requirements and task constraints (Ericsson \& Lehmann, 1996).

High performers with a formal leadership role contributed more to the overall meeting process and to process regulation than did high performers without a formal leadership role. However, high performers with a leadership role did not differ from team leaders who were moderate performers. These findings imply that the formal role has a substantial impact on meeting participation (for similar findings, cf. Larson et al., 1996; Ruback, Dabbs, \& Hopper, 1984). Moreover, high performance is reflected in software professionals' meeting participation when they are ordinary teammembers but not when they are team leaders. These findings suggest that high performers' meeting behavior becomes dominated by their leadership role when they participate as team leaders.

With respect to their meeting participation, high performers with no formal leadership role held a intermediate position between moderate performers and team leaders. This participation pattern suggests that high performers tend to play an informal leadership role within their teams.

\section{Strengths and Limitations}

Previous expertise research on high and moderate performers' involvement in cooperation relied heavily on self-reports and other data where both the identification and description of high performers stemmed from the same source (e.g., coworkers). The present study overcame these shortcomings by making use of observational data. Thus, alternative explanations associated with findings of previous studies (e.g., more positive self-reports provided by high performers or general halo effects in descriptions by coworkers) could be ruled out.

This study is based on data gathered in real team meetings held in real work teams. With this approach aiming at a high external validity, the study described how individuals differ in contributing to company decisions and to the development of software products to be used by a large number of customers. Moreover, a variety of different meetings were analyzed. These meetings differed largely with respect to the software to be developed, software life cycle, and meeting content and duration. These variations imply that the findings can be generalized across a variety of meeting situations.

One limitation of this study concerns the method of measuring high performance. Although peer nominations were conducted before the observation of the meetings, one might argue that peers based their nominations primarily on high performers' earlier participation in meeting processes and not on these persons' actual performance. For example, research on emergent leadership has shown that group members who contribute extensively to the group process are chosen as group leaders (Mullen, Salas, \& Driskell, 1989). However, several arguments question the applicability of the findings from emergent leadership research to the present study. First, in studies on emergent leadership, a team member had to be chosen to fulfil the leadership role within the group. In the present study, however, the peer nominations aimed at nominating a high performer. One can assume that individuals focus more on meeting participation when they are asked to 
elect a leader than when they nominate a high performer. Second, research in organizational settings has shown that peer nominations provide valid performance measures (Harris \& Schaubroeck, 1988; Norton, 1992). In actual work settings, where coworkers have ample opportunities for observing each others' typical work performance, it is very unlikely that individuals can mislead their coworkers (e.g., by being talkative in meetings) and hide their actual performance level over longer periods of time (Borman, 1991). Taken together, although I cannot completely rule out the possibility that peer nomination outcomes were partially influenced by prior participation in cooperation processes, it is very unlikely that the study findings are based only on the specific performance measure used.

Because the study was conducted in one single professional domain, one might question the generalizability of the findings. However, there are no reasons to believe that the findings are based on technical specificities of the software domain. Rather, one can assume that the findings generalize to other areas where knowledge has to be communicated continuously and where important decisions are made during team meetings.

\section{Alternative Interpretations}

This study's findings suggest that high performers possess superior cooperation competencies and that these cooperation competencies differentiate them from moderate performers. Furthermore, the findings on process regulation activities are in line with Ericsson and Lehmann's (1996) description that high performers show a better adaptation to task constraints and task requirements. However, there are alternative interpretations.

High performers' behavior in unstructured meetings resembles their approach to individual problem solving to a high degree. When working individually on a task, high performers put more emphasis on goal setting, problem comprehension, and feedback processing (Klemp \& McClelland, 1986; Sonnentag, 1998; Vitalari \& Dickson, 1983). Thus, the question arises of whether high performers' process regulating activities shown in unstructured meetings just reflect their superior problem-solving skills. If this were the case, it would imply that high performers' extensive involvement in communication and cooperation processes is not a unique or core aspect of their expertise (cf. Ericsson \& Lehmann, 1996) but, rather, a consequence of their specific problem-solving approaches to task accomplishment.

Research conducted within the social cognitive theory (Wood, 1996; Wood \& Bandura, 1989) suggests that particularly in complex situations, high performers show specific approaches to task accomplishment, such as requesting information and analyzing action consequences. Poorly structured meetings can be seen as highly complex situations because they do not just require contributions to the contentrelated aspects of the meeting, participants also need to recognize and understand the relationship between a specific discussion going on at the moment and the meeting process as a whole. As a consequence, poorly structured meetings ask for specific cognitive competencies to deal with complex situations. This situation would imply that high performers' involvement in complex and poorly structured cooperation processes can be mainly accounted for by their superior knowledge and problem-solving skills and not by superior cooperation competencies. To examine this interpretation, further studies are needed. These studies should test whether cooperation activities shown in cooperation settings explain variance in individual performance beyond the variance explained by problem-solving activities shown in individual task settings.

The present study showed that high performers contributed more to team meetings than did moderate performers. Within the argument of this article, high performers' greater degree of participation was attributed to specific characteristics of these high performers, particularly their knowledge and their ability to adapt to task requirements. Moderate performers' lesser degree of participation would be explained by insufficient knowledge and lower ability to adapt the task requirements. However, the literature on group performance offers an additional interpretation. Research on social loafing and free riding has shown that group members withhold effort when they feel that their contribution is dispensable (Karau \& Williams, 1993; Kidwell \& Bennett, 1993; Sheppard, 1993). Moderate performers may experience their contributions as more dispensable than those of high 
performers. As a consequence, they will refrain from participating a lot in team meetings, particularly in difficult and poorly structured situations. In contrast, high performers know that their contributions are necessary and unique and therefore will participate more in the meeting process. Moreover, high performers may even try to compensate for the relatively low effort and performance of their moderately performing coworkers (Williams \& Karau, 1991). This interpretation implies that it is not the difference in knowledge and ability per se that accounts for participation differences between high and moderate performers but differences in experienced indispensability and importance of the respective contributions. It might be that both individual characteristics and group processes have an impact on meeting participation. However, it is unlikely that only group processes, reflected in an individual's increased effort and willingness to compensate for other teammembers' poor participation, are sufficient for substantially contributing to the accomplishment of complex software design tasks. Knowledge and the ability to act in unstructured situations are necessary for discussing the relevant issues and verbalizing solution ideas. Nevertheless, future studies are needed to disentangle processes that are based on high and moderate performers' actual characteristics and processes that are based on withheld effort because of assumed dispensability of one's contribution.

\section{Implications for Theory Development and Future Research}

This study contributes to the development of a theory of expertise (Ericsson \& Smith, 1991b). The study revealed that high performers differ from moderate performers with respect to their involvement in cooperation processes. Although it is not yet unequivocally known whether this difference is caused only by high performers' specific characteristics or additionally by group processes, the findings make clear that differences between high and moderate are also highly salient in cooperation settings. Moreover, the study showed that high performers' high adaptation to task requirements applies not only to cognitive aspects of a task, but also to requirements of a cooperation setting.

Regardless of its causes, high performers' high involvement in cooperation processes might have an impact on their future competence development. Research on self-explanation has shown that explaining ideas and facts to oneself improves future performance (Chi, de Leeuw, Chiu, \& LaVancher, 1994). The same is presumably true for explanations given to others. High performers' high degree of participation during meetings allows them to create and use ample opportunities to provide explanations. Providing explanations in turn improves one's own understanding of the subject and therefore contributes to competence improvement. Moreover, as research on "cognitive tuning" suggests (Zajonc, 1960), high performers' anticipation of their active role in cooperation processes might additionally affect how they learn and organize new information. Expecting that they will have to explain new material to others and answer questions will stimulate them to develop more differentiated and complex cognitive structures.

This study offers a number of suggestions for future research. First, studies are needed in which both problem-solving processes and cooperation processes, such as involvement in meetings, are measured. Such studies would enable an analysis of whether high performers' specific types of meeting participation are more than a by-product of their superior problemsolving processes. Second, future research should address the question of whether high performers' more extensive meeting participation is caused by these persons' individual characteristics as opposed to group processes. Third, the effects of high performers' involvement in the meeting process on group performance should be examined. When regarding individual high performance in a wider context, it is important to know whether high performers' contributions are more relevant for efficient team meetings than are moderate performers' contributions. Finally, to allow a conclusive interpretation of the data, it is important to note that researchers should identify high and moderate performers by an objective performance measure, such as performance in a standardized task.

To conclude, this observational study in real work teams showed that high performers contribute more to team meetings and that the specific type of their contributions depends on the structuredness of the meeting. Given this study's finding of a relationship between high 
performance and observable participation in cooperation processes, future research should address the underlying factors and processes more explicitly.

\section{References}

Altman, P. M. E. (1979). Detecting relationships between categorical variables observed over time: A problem of deflating a chi-squared statistic. Applied Statistics, 28, 115-125.

Ashford, S. J., \& Tsui, S. A. (1991). Self-regulation for managerial effectiveness: The role of active feedback seeking. Academy of Management Journal, 34, 251-280.

Badke-Schaub, P., \& Frankenberger, E. (1996). Von den Daten zum Modell: Eine Empirische Untersuchung von Gruppenarbeit in der Konstruktionspraxis [From the data to the model: An empirical study on group work in the design industry (Memorandum No. 14). Location: Lehrstuhl Psychologie II der Universität Bamberg.

Borman, W. C. (1991). Job behavior, performance, and effectiveness. In M. D. Dunnette \& L. M. Hough (Eds.), Handbook of industrial and organizational psychology (2nd ed., Vol. 2, pp. 271326). Palo Alto, CA: Consulting Psychologists Press.

Bottger, P. C. (1984). Expertise and air time as basis of actual and perceived influence in problem solving groups. Journal of Applied Psychology, 69, $214-221$.

Cannon-Bowers, J. A., Tannenbaum, S. I., Salas, E., \& Volpe, C. E. (1995). Defining competencies and establishing team training requirements. In R. A. Guzzo, E. Salas, \& Associates (Eds.), Team effectiveness and decision making in organizations (pp. 333-380). San Francisco, CA: Jossey-Bass.

Chi, M. T. H., de Leeuw, N., Chiu, M.-H., \& LaVancher, C. (1994). Eliciting self-explanations improves understanding. Cognitive Science, 18, 439477.

Cox, K. (1987). Meetings, meetings, meetings. Educational and Child Psychology, 4, 54-61.

Curtis, B., Krasner, H., \& Iscoe, N. (1988). A field study of the software design process for large systems. Communications of the ACM, 31, 1268 1287.

Dörner, D., \& Schölkopf, J. (1991). Controlling complex systems; or expertise as "grandmother's know-how." In K. A. Ericsson \& J. Smith (Eds.), Toward a general theory of experise: Prospects and limits (pp. 218-239). Cambridge, England: Cambridge University Press.

Ericsson, K. A., \& Lehmann, A. C. (1996). Expert and exceptional performance: Evidence of maxi- mal adaptation to task constraints. Annual Review of Psychology, 47, 273-305.

Ericsson, K. A., \& Smith, J. (1991a). Prospects and limits of the empirical study of expertise: An introduction. In K. A. Ericsson \& J. Smith (Eds.), Toward a general theory of expertise: Prospects and limits (pp. 1-38). Cambridge, England: Cambridge University Press.

Ericsson, K. A., \& Smith, J. (Eds.). (1991b). Toward a general theory of expertise. Cambridge, England: Cambridge University Press.

Fischer, A., \& Northey, M. (1993). Impact. A guide to business communication. Englewood Cliffs, NJ: Prentice Hall.

Ford, J. K., \& Kraiger, K. (1995). The application of cognitive constructs and principles to the instructional systems model of training: Implications for needs assessment, design, and transfer. In C. L. Cooper \& I. T. Robertson (Eds.), International review of industrial and organizational psychology (Vol. 10, pp. 1-48). Chichester, England: Wiley.

Freedman, D. P., \& Weinberg, G. M. (1982). Handbook of walkthroughs, inspections and technical reviews. Boston: Little, Brown.

Frensch, P. A., \& Sternberg, R. J. (1989). Expertise and intelligent thinking: When is it worse to know better? In R. J. Sternberg (Ed.), Advances in the psychology of human intelligence (Vol. 5, pp. 157188). Hillsdale, NJ: Erlbaum.

Green, A. J. K., \& Gilhooly, K. J. (1992). Empirical advances in expertise research. In M. T. Keane \& K. J. Gilhooly (Eds.), Advances in the psychology of thinking (Vol. 1, pp. 45-70). New York: Harvester Wheatsheaf.

Guzzo, R. A., \& Shea, G. P. (1992). Group performance and intergroup relations in organizations. In M. D. Dunnette \& L. M. Hough (Eds.), Handbook of industrial and organizational psychology (2nd ed., Vol. 3, pp. 269-313). Palo Alto, CA: Consulting Psychologists Press.

Hacker, W., \& Vaic, H. (1973). Psychologische Analyse interindividueller Leistungsdifferenzen als eine Grundlage von Rationalisierungsbeiträgen [Psychological analysis of interindividual performance differences as a basis of rationalization processes]. In W. Hacker, W. Quaas, H. Raum, \& H.-J. Schulz (Eds.), Psychologische Arbeitsuntersuchung (pp. 109-131). Berlin, East Germany: Deutscher Verlag der Wissenschaften.

Hackman, J. R., \& Morris, C. G. (1975). Group tasks, group interaction process, and group performance effectiveness: A review and proposed integration. In L. Berkowitz (Ed.), Advances in experimental social psychology (Vol. 8, pp. 45-99). New York: Academic Press.

Harris, M. M., \& Schaubroeck, J. (1988). A metaanalysis of self-supervisor, self-peer, and peer- 
supervisor ratings. Personnel Psychology, 41, 4362.

Jehn, K. A., \& Shah, P. P. (1997). Interpersonal relationships and task performance: An examination of mediating processes in friendship and acquaintance groups. Journal of Personality and Social Psychology, 72, 775-790.

Kanfer, R., \& Ackerman, P. L. (1989). Motivation and cognitive abilities: An integrative/aptitudetreatment interaction approach to skill acquisition. Journal of Applied Psychology, 74, 657-690.

Karau, S. J., \& Williams, K. D. (1993). Social loafing: A meta-analytic review and theoretical integration. Journal of Personality and Social Psychology, 65, 681-706.

Kidwell, R. E. J., \& Bennett, N. (1993). Employee propensity to withhold effort: A conceptual model to intersect three avenues of research. Academy of Management Review, 18, 429-456.

Klemp, G. O., \& McClelland, D. C. (1986). What characterizes intelligent functioning among senior managers? In R. J. Sternberg \& R. K. Wagner (Eds.), Practical intelligence: Nature and origin of competence in the everyday world (pp. 31-50). Cambridge, England: Cambridge University Press.

Kriesberg, M., \& Guetzkow, H. (1950). The use of conferences in the administrative process. Public Administration Review, 10, 93-98.

Landis, J. R., \& Koch, G. G. (1977). The measurement of observer agreement for categorical data. Biometrics, 33, 159-174.

Larson, J. R. J., Christensen, C., Abbott, A. S., \& Franz, T. M. (1996). Diagnosing groups: Charting the flow of information in medical decision-making teams. Journal of Personality and Social Psychology, 71, 315-330.

Leithwood, K., \& Steinbach, R. (1995). Expert problem solving: Evidence from school and district leaders. Albany: State University of New York Press.

Maier, N. R. F. (1967). Assets and liabilities in group problem solving: The need for an integrative function. Psychological Review, 74, 239-249.

McClintock, C. C., Brannon, D., \& Maynard, M. S. (1979). Applying the logic of sample surveys to qualitative case studies: The case cluster method. Administrative Science Quarterly, 24, 612-629.

Mullen, B., Salas, E., \& Driskell, J. E. (1989). Salience, motivation, and artifact as contributions to the relation between participation rate and leadership. Journal of Experimental Social Psychology, $25,545-559$.

Norton, S. M. (1992). Peer assessments of performance and ability: An exploratory meta-analysis of statistical artifacts and contextual moderators. Journal of Business and Psychology, 6, 387-399.

Olson, G. M., Olson, J. S., Carter, M. R., \& Storrøsten, M. (1992). Small group design meetings:
An analysis of collaboration. Human-Computer Interaction, 7, 347-374.

Riedl, T. R., Weitzenfeld, J. S., Freeman, J. T., Klein, G. A., \& Musa, J. (1991). What we have learned about software engineering expertise. Proceedings of the Fifth Software Engineering Institute Conference on Software Engineering Education (pp. 261-270). New York: Springer.

Ruback, R. B., Dabbs, J. M., \& Hopper, C. H. (1984). The process of brainstorming: An analysis with individual and group vocal parameters. Journal of Personality and Social Psychology, 47, 558-567.

Schenk, K. D., Vitalari, N. P., \& Davis, K. S. (1998). Differences between novice and expert system analysts: What do we know and what do we do? Journal of Management Information Systems, 15, 9-50.

Schwartzman, H. B. (1989). The meeting: Gatherings in organizations and communities. New York: Plenum.

Sheppard, J. A. (1993). Productivity loss in performance groups: A motivation analysis. Psychological Bulletin, 113, 67-81.

Smith, M. U., \& Good, R. (1984). Problem solving and classical genetics: Successful versus unsuccessful performance. Journal of Research in Science Teaching, 21, 895-912.

Sonnentag, S. (1995). Excellent software professionals: Experience, work activities, and perceptions by peers. Behaviour \& Information Technology, 14, 289-299.

Sonnentag, S. (1998). Expertise in professional software design: A process study. Joumal of Applied Psychology, 83, 703-715.

Sonnentag, S. (2000). Expertise at work: Experience and excellent performance. In C. L. Cooper \& I. T. Robertson (Eds.), International review of industrial and organizational psychology (pp. 223-264). Chichester, England: Wiley.

Stasser, G., \& Stewart, D. (1992). Discovery of hidden profiles by decision making groups: Solving a problem versus making a judgement. Journal of Personality and Social Psychology, 63, 426-434.

Stein, E. W. (1995). Social and individual characteristics of organizational experts. International Journal of Expert Systems, 8, 121-143.

Stevens, M. J., \& Campion, M. A. (1994). The knowledge, skill, and ability requirements for teamwork: Implications for human resource management. Journal of Management, 20, 503-530.

Stewart, D. D., \& Stasser, G. (1995). Expert role assignment and information sampling during collective recall and decision making. Journal of Personality and Social Psychology, 69, 619-628.

Tannenbaum, S. I., Salas, E., \& Cannon-Bowers, J. A. (1996). Promoting team effectiveness. In M. A. West (Ed.), Handbook of work group psy- 
chology (pp. 503-529). Chichester, England: Wiley.

Tripoli, A. M. (1998). Planning and allocating: Strategies for managing priorities in complex jobs. $E \boldsymbol{u}$ ropean Journal of Work and Organizational Psychology, 7, 455-476.

Tschan, F. (1995). Communication enhances small group performance if it conforms task requirements: The concept of the ideal communication cycles. Basic and Applied Social Psychology, 17, 371-393.

Turner, J. C. (1991). Social influence. Buckingham, United Kingdom: Open University Press.

Turner, R. H., \& Colomy, P. (1988). Role differentiation: Orienting principles. Advances in Group Processes, 5, 1-27.

Vitalari, N. P., \& Dickson, G. W. (1983). Problem solving for effective systems analysis: An experimental exploration. Communications of the ACM, 26, 948-956.

Wagner, R. K., \& Sternberg, R. J. (1985). Practical intelligence in real-world pursuits: The role of tacit knowledge. Journal of Personality and Social Psychology, 49, 436-458.

Walz, D. B., Elam, J. J., Krasner, H., \& Curtis, B. (1987). A methodology for studying software design teams: An investigation of conflict behaviors in the requirement definition phase. In G. M. Olson, S. Sheppard, \& E. Soloway (Eds.), Empirical studies of programmers: Second workshop (pp. 83-99). Norwood, NJ: Ablex.

Weldon, E., Jehn, K. A., \& Pradhan, P. (1991).
Processes that mediate the relationship between a group goal and improved group performance. Journal of Personality and Social Psychology, 61, 555-569.

Weldon, E., \& Weingart, L. R. (1993). Group goals and group performance. British Joumal of Social Psychology, 32, 307-334.

West, M. A. (1996). Reflexivity and work group effectiveness: A conceptual integration. In M. A. West (Ed.), Handbook of work group psychology (pp. 555-579). Chichester, England: Wiley.

West, M. A., Borrill, C. S., \& Unsworth, K. L. (1998). Team effectiveness in organizations. In C. L. Cooper \& I. T. Robertson (Eds.), International review of industrial and organizational psychology (Vol. 13, pp. 1-48). Chichester, England: Wiley.

Williams, K. D., \& Karau, S. J. (1991). Social loafing and social compensation: The effects of expectations of co-worker performance. Journal of Personality and Social Psychology, 61, 570-581.

Wood, R. E. (1996, August). A social cognitive analysis of working smarter on complex tasks. Paper presented at the Academy of Management Annual Meeting 1996, Cincinnati, OH.

Wood, R. E., \& Bandura, A. (1989). Social cognitive theory of organizational management. Academy of Management Review, 14, 361-384.

Yin, R. K. (1981). The case study crisis: Some answers. Administrative Science Quarterly, 26, 5865.

Zajonc, R. B. (1960). The process of cognitive tuning in communication. Journal of Abnormal and Social Psychology, 61, 159-167. 